\title{
Enterobiasis and strongyloidiasis and associated co-infections and morbidity markers in infants, preschool- and school-aged children from rural coastal Tanzania: a cross-sectional study
}

Nahya Salim ${ }^{1,2,3,4}$, Tobias Schindler ${ }^{1,4,5}$, Ummi Abdul ${ }^{1}$, Julian Rothen ${ }^{1,4,5}$, Blaise Genton ${ }^{3,4,6}$, Omar Lweno ${ }^{1}$, Alisa S Mohammed', John Masimba', Denis Kwaba', Salim Abdulla', Marcel Tanner ${ }^{3,4}$,

Claudia Daubenberger ${ }^{4,5}$ and Stefanie Knopp ${ }^{3,4,7^{*}}$

\begin{abstract}
Background: There is a paucity of data pertaining to the epidemiology and public health impact of Enterobius vermicularis and Strongyloides stercoralis infections. We aimed to determine the extent of enterobiasis, strongyloidiasis, and other helminth infections and their association with asymptomatic Plasmodium parasitaemia, anaemia, nutritional status, and blood cell counts in infants, preschool-aged (PSAC), and school-aged children (SAC) from rural coastal Tanzania.

Methods: A total of 1,033 children were included in a cross-sectional study implemented in the Bagamoyo district in 2011/2012. Faecal samples were examined for intestinal helminth infections using a broad set of quality controlled methods. Finger-prick blood samples were subjected to filariasis and Plasmodium parasitaemia testing and full blood cell count examination. Weight, length/height, and/or mid-upper arm circumference were measured and the nutritional status determined in accordance with age.
\end{abstract}

Results: E. vermicularis infections were found in $4.2 \%$ of infants, $16.7 \%$, of PSAC, and $26.3 \%$ of SAC. S. stercoralis infections were detected in 5.8\%, 7.5\%, and $7.1 \%$ of infants, PSAC, and SAC, respectively. Multivariable regression analyses revealed higher odds of enterobiasis in children of all age-groups with a reported anthelminthic treatment history over the past six months (odds ratio (OR): 2.15; 95\% confidence interval (Cl): 1.22 - 3.79) and in SAC with a higher temperature (OR: 2.21; Cl: 1.13 - 4.33). Strongyloidiasis was associated with eosinophilia (OR: 2.04; Cl: 1.20-3.48) and with Trichuris trichiura infections (OR: 4.13; Cl: 1.04-16.52) in children of all age-groups, and with asymptomatic Plasmodium parasitaemia (OR: 13.03; Cl: 1.34 - 127.23) in infants. None of the investigated helminthiases impacted significantly on the nutritional status and anaemia, but moderate asymptomatic Plasmodium parasitaemia was a strong predictor for anaemia in children aged older than two years (OR: 2.69; 95\% Cl: $1.23-5.86$ ).

Conclusions: E. vermicularis and S. stercoralis infections were moderately prevalent in children from rural coastal Tanzania. Our data can contribute to inform yet missing global burden of disease and prevalence estimates for strongyloidiasis and enterobiasis. The association between $S$ stercoralis and asymptomatic Plasmodium parasitaemia found here warrants further comprehensive investigations.

Keywords: Asymptomatic Plasmodium parasitaemia, Anaemia, Anthropometric measures, Co-infection, Enterobius vermicularis, Haematology, Hookworm, Soil-transmitted helminths, Strongyloides stercoralis, Tanzania, Trichuris trichiura

\footnotetext{
*Correspondence: s.knopp@unibas.ch

${ }^{3}$ Department of Epidemiology and Public Health, Swiss Tropical and Public

Health Institute, Basel, Switzerland

${ }^{4}$ University of Basel, Basel, Switzerland

Full list of author information is available at the end of the article
}

C Biomed Central (c) 2014 Salim et al.; licensee BioMed Central Ltd. This is an Open Access article distributed under the terms of the Creative Commons Attribution License (http://creativecommons.org/licenses/by/4.0), which permits unrestricted use, distribution, and reproduction in any medium, provided the original work is properly credited. The Creative Commons Public Domain Dedication waiver (http://creativecommons.org/publicdomain/zero/1.0/) applies to the data made available in this article, unless otherwise stated. 


\section{Background}

Soil-transmitted helminth infections belong to the neglected tropical diseases [1]. The most common soil-transmitted helminths are roundworms (Ascaris lumbricoides), whipworms (Trichuris trichiura), and hookworms (Ancylostoma duodenale and Necator americanus). Infections are acquired via the ingestion of the parasites' eggs, for example with contaminated food, or in case of hookworms via larvae penetrating bare skin $[2,3]$. The adult worms live in the intestines of humans, and eggs or larvae are excreted with faeces and thrive in the soil. Hence, infections are particularly prevalent in areas, where hygiene and sanitation are low and where the environment favours a rapid transmission. It is estimated that globally around 1.45 billion people are infected with at least one intestinal helminth species, and a global burden of 5.2 million disability adjusted life years (DALYs) is attributed to these infections [4-6].

In addition to the four major soil-transmitted helminth species, there are two intestinal nematodes infecting humans, the threadworm Strongyloides stercoralis and the pinworm Enterobius vermicularis that are mostly neglected in prevalence reports and global burden of disease estimates due to their rather unpleasant and cumbersome diagnosis with the Baermann and/or Koga agar plate methods or adhesive tape test, respectively, and due to difficulties to assess associated morbidity [1,2,7-10].

S. stercoralis has an intra- and extra-human lifecycle during which the parasite can reproduce asexually and sexually, respectively. Larvae that hatched from eggs within the intestines are able to penetrate the intestinal wall and can perpetuate the lifecycle within the human host for decades after initial exposure [2,11]. Infections are mostly mild and often asymptomatic in otherwise healthy individuals [12]. Skin lesions, pulmonary and gastro-intestinal symptoms, and blood eosinophilia are reported as unspecific disease markers [10,13-17]. Chronically infected immunocompromised patients, however, are at high risk of developing a lethal hyper-infection syndrome, caused by proliferating tissue-invasive larvae that might carry bacteria from the intestines to organs, leading to systemic infections, multiorgan failure and systemic sepsis $[1,12,18]$. It is estimated that S. stercoralis affects between $10 \%$ and $40 \%$ of the population in tropical- and sub-tropical countries, but adequate information is lacking, particularly for the high-risk areas including Sub-Saharan Africa and Southeast Asia [19]. Global burden of disease estimates do not exist for this parasite $[5,19,20]$ and strongyloidiasis remains an underestimated health problem [21]. Good reliable data on infection, morbidity, and indisputable causal links between them, are urgently needed to make the public health argument for a guided response against S. stercoralis [7].

E. vermicularis is transmitted via the ingestion of eggs contained in dust, water, or sticking on hands and food.
The female adults live in the cecum and large intestines and migrate to the anus to deposit their eggs on the perianal skin [2]. Since eggs become infective within hours, autoinfection is possible [22]. Enterobiasis includes symptoms such as intense pruritus in the perianal area, which can lead to insomnia, restlessness, and irritability. Moreover, the adult pinworms can migrate into the appendix or genital tract, causing appendicitis and genitourinary complications [23,24]. Ectopic infections of liver, lung, kidneys, and other organs occur infrequently [24,25]. Enterobiasis is considered the most common helminth infection worldwide [26]. It is estimated that globally 4-28\% of children are infected [3], but recent and profound prevalence and burden estimates are missing, particularly for Sub-Saharan Africa.

The neglect of strongyloidiasis and enterobiasis in most studies pertaining to soil-transmitted helminth infections results in a knowledge gap about their potential impact on co-infections and the nutritional status of the host. While it is widely acknowledged that helminth infections modulate immune responses and might influence the acquisition and outcomes of diseases such as malaria, tuberculosis (TB), and human immunodeficiency virusacquired immune deficiency syndrome (HIV-AIDS), the exact mechanisms are not known [27-37]. Research on this topic has gained much interest over the past years, but results are inconsistent. Multiple dimensions seem to be involved, including helminth species, infection intensity, and the host's age, genetics, and immunological and nutritional status $[38,39]$.

The IDEA research program is designed to intensively study the immunological interplay between helminth infections and malaria, TB, and HIV-AIDS (http://ec.europa. eu/research/health/infectious-diseases/neglected-diseases/ projects/014_en.html). Of course, to obtain reliable results, not only the presence of major helminth species, but also infections with $S$. stercoralis and $E$. vermicularis need to be taken into account. Here, we present, to our knowledge for the first time, the extend of strongyloidiasis and enterobiasis, besides other helminthiases, in infants, preschool-aged children (PSAC), and school-aged children (SAC) from rural coastal Tanzania that participated in a cross-sectional study implemented to recruit participants for the IDEAmalaria study arm in the Bagamoyo district, United Republic of Tanzania. We also show anthropometric and haematological characteristics of the study group and associations found between the individual helminth species infections, between helminth infections and asymptomatic Plasmodium infections and between helminth infections and anthropometric status, anaemia, and additional haematological parameters in different age-groups. With this report we aim to shed more light on the distribution and public health importance of two highly neglected soil-transmitted helminth species and therefore 
to contribute to inform yet missing global burden and prevalence estimates.

\section{Methods}

\section{Ethics statement}

The protocol for the IDEA project conducted at the Bagamoyo Research and Training Center of the Ifakara Health Institute (IHI-BRTC) in Bagamoyo, United Republic of Tanzania, was approved by the institutional research commissions of the Swiss Tropical and Public Health Institute (Swiss TPH; Basel, Switzerland) and the IHI. Ethical approval for the study was obtained from the Ethikkomission beider Basel (EKBB; Basel, Switzerland; reference number: 257/08) and the National Institution for Medical Research of Tanzania (NIMR; Dar es Salaam, United Republic of Tanzania; reference number: NIMR/ HQ/R.8a/Vol.IX/1098). The study was monitored by the IHI internal monitoring team in collaboration with the Pan African Collaboration for the Evaluation of Antituberculosis Antibiotics (PanACEA) and Swiss TPH.

Local district, community, school, and health authorities were informed about the purpose and procedures of the study and their acceptance for the implementation was sought. Individuals eligible to be screened and to potentially participate in one of the study arms of IDEA were informed in detail about the aims of the study, the risks and benefits of study participation, and the extend of time involvement in case of their participation [9]. It was pointed out that participation was voluntary and that participants could withdraw from the study at any time without further obligation. All adult participants and in case of children aged ten years or younger (ten years being the age-limit of children eligible for inclusion in the IDEA-malaria study arm) their parents or legal guardians, were asked to sign a written informed consent sheet if they agreed to participate. Participants' privacy was preserved by de-identification of the dataset. Participants' names were replaced by individual identification codes and all information pertaining to names, geographical locations, and dates of birth, sample collection, and sample examination was removed from the dataset.

Patients with helminthiases, malaria, TB, HIV-AIDS, and/or other medical conditions received treatment according to the national treatment guidelines of the United Republic of Tanzania. Accordingly, participants of our cross-sectional survey that were infected with helminths were treated with albendazole $(400 \mathrm{mg}$ single oral dose) against common soil-transmitted helminth infections, S. stercoralis and E. vermicularis, or praziquantel (40 mg/kg) against Schistosoma infections. Participants with asymptomatic Plasmodium parasitaemia or clinical malaria were treated with Artemether Lumefantrine and children with severe malaria received Quinine.

\section{Study area}

All participants included in the present analysis resided in one among 12 villages or small towns in the Bagamoyo district, belonging to the Pwani region in the United Republic of Tanzania. These settlements are located in a rural environment approximately 20-60 kilometres from Bagamoyo, which is a historical town located directly at the coast along the Indian Ocean, 75 kilometres north of Dar es Salaam. The population of the Bagamoyo district was estimated at 311,740 inhabitants in the 2012 census [40]. The IHI-BRTC, where the laboratory work was conducted, is located right beside the Bagamoyo District Hospital in the heart of the town.

The average temperature for the region is $28^{\circ} \mathrm{C}$ and there are two annual rainy seasons, the heavy Masika rains from March to June and the light Vuli rains from October to December. The leading source of income of the region is cash crop production of coconuts, fruits and cashew nuts, livestock farming and, yet to a lesser extent, fishing and salt mining [41]. The inhabitants of the region are mainly smallholder farmers engaged in food crop production such as vegetables, cassava, pulses, maize, and paddy [41].

\section{Study design and participant recruitment}

The IDEA study is designed as longitudinal short-term study with three study arms [9]. In the present study, we focused on results of a cross-sectional study, implemented to recruit children aged two months to ten years with asymptomatic Plasmodium parasitaemia for the IDEAmalaria study arm. In that arm, a sample size of 100 children with asymptomatic Plasmodium parasitaemia was required. Expecting a prevalence of $10 \%$ of asymptomatic Plasmodium parasitaemia (as found in previous, yet unpublished studies in the Bagamoyo area), we had to enrol about $\sim 1,000$ children living in the Bagamoyo district in the cross-sectional study. The fieldwork for recruitment and data collection started in early 2011 and was concluded in November 2012.

\section{Field procedures}

Before the onset of the study, sensitization and information meetings were hold with community leaders, village health care workers (VHCW), teachers, and local clinicians. Parents were informed by VHCW about the study and asked to bring the children that they considered as healthy to meeting points to participate in the health screening to recruit children into the asymptomatic IDEAmalaria study arm on a specific day. At the meeting point, the study aims and procedures were explained in detail and in lay terms to the children and their accompanying parent or legal guardian. If the patient or parent/legal guardian orally assented to participation, the parent/legal guardian was given an information sheet and asked to 
provide a written informed consent for the child to participate. In case of illiteracy, a thumbprint signature was obtained.

Upon submission of the signed consent sheet, the participant's demographics, vitals, clinical signs and symptoms, and reported anthelmintic treatment history (treatment with albendazole or mebendazole within the past 6 months) and use of bed nets were entered in standardized forms. Children's axillary temperature, height or length (measured with standardized height/length boards from the World Health Organization (WHO)/United Nations Children's Fund (UNICEF)), weight (measured with a 25 kilogram hanging scale (C. M. S. Weighing Equipment Ltd., London, United Kingdom) for light children and with a seca weighing scale (seca Deutschland, Hamburg, Germany) for heavier children), and mid-upper arm circumference (MUAC; measured with the standard UNICEF MUAC tape (S0145620 MUAC, Child 11.5 Red/PAC-50)) were recorded. A finger-prick blood sample $(1.0 \mathrm{ml})$ was collected and stored on ice immediately after collection until examination in the laboratory at IHI-BRTC. Each participant was provided with (i) two plastic containers $(100 \mathrm{ml})$ with lid for urine and stool collection, respectively, and (ii) an adhesive tape $(50 \times 20 \mathrm{~mm})$ and a microscope slide, all labelled with an individual identifier code. The participants were invited to collect an own urine and morning stool sample of sufficient size (i.e. to fill half of the container) to perform all laboratory examinations. Additionally, they were instructed to wash their buttocks before going to bed and, in the morning after wake up and before taking a shower, to apply the adhesive tape on their anus before sticking it to the microscope slide. The filled containers and adhesive tape slides were collected by a VHCW the next day around noon and transferred to the Helminth Unit laboratory of the IHI-BRTC, where all stool and urine samples were examined.

\section{Laboratory procedures}

The blood samples were examined for a full blood cell count including a differential white blood cell count using an externally quality controlled Sysmex XS-800 Haematology Analyser (Sysmex Deutschland GmbH, Norderstedt, Germany). Malaria parasitaemia was assessed using the SD Bioline Malaria Ag Pf/Pan 05FK60 rapid test (Standard Diagnostics, Kyonggi, Republic of Korea) and by microscopy. For the latter purpose, two thick blood smear slides (using $6 \mu \mathrm{l}$ of blood) per patient were prepared, stained with Giemsa, and examined by two certified malaria microscopists who independently counted the number of asexual Plasmodium parasite stages per up to 500 white blood cells counts, depending on the level of parasitaemia [42]. Plasmodium species were not differentiated, but it is widely assumed that $P$. falciparum is the major cause of malaria in Tanzania [43]. Blood samples from children who entered the study from July 2012 onwards were additionally examined for Wuchereria bancrofti antigen using the Binax NOW Filariasis rapid immunochromatic test (ICT)-card (Inverness Medical Professional Diagnostics; Scarborough, ME, United States of America). In brief and according to the manufacturer's manual, $100 \mu \mathrm{l}$ of whole blood were transferred on the ICT-card. Subsequently, the test card was closed and incubated for 10 min before the result was read.

Stool and urine samples were processed by experienced laboratory technicians as described in detail elsewhere [9]. Firstly, the Baermann method was applied for the detection of S. stercoralis larvae [44]. Secondly, during the Baermann incubation time, from the remainder of the stool sample of each participant duplicate Kato-Katz thick smear slides were prepared using a $41.7 \mathrm{mg}$ template [45] for the diagnosis and number of $A$. lumbricoides, hookworm, T. trichiura and S. mansoni eggs. Thirdly, adhesive tape slides were microscopically examined for the presence of $E$. vermicularis eggs. Fourthly, the urine sample of each participant was investigated for microhaematuria using a dipstick (Haemastix; Siemens Healthcare Diagnostics, Eschborn, Germany) and for S. haematobium eggs by duplicate urine filtration slides (hydrophilic polycarbonate membrane filter; pore size 20 micron, diameter $13 \mathrm{~mm}$; Sterlitech, Kent, WA, United States of America) [46]. Fifthly, the following morning, before new samples arrived, a subsample of each individual's stool $(\sim 1 \mathrm{~g})$, which had been preserved in sodium acetate acetic acid formalin (SAF) over night, was examined for the presence and number of helminth eggs with the FLOTAC dual technique [47] using flotation solution 2 (FS2; saturated sodium chloride $(\mathrm{NaCl})$ solution; specific gravity (s.g.): 1.20) and FS7 (zinc sulfate ( $\mathrm{ZnSO} 4 \mathrm{7H} 2 \mathrm{O}$ ) solution; s.g.: 1.35). At least $10 \%$ of the blood smear, Kato-Katz thick smear, adhesive tape and urine filtration slides were subjected to re-examination for quality control by independent trained microscopists blinded to the initial result.

\section{Data management and statistical analysis}

Each participant's data were entered manually in the participant's case report form (CRF), subsequently transferred into an electronic data base (Microsoft Access 2010, Microsoft Corporation; Redmont, WA, United States of America; and DMSys, SigmaSoft International; Chicago, IL, United States of America) and finally transferred, cleaned, and analysed using STATA version 9.2 (StataCorp.; College Station, TX, United States of America). Anthropometric z-scores were calculated using the WHO Anthro and AnthroPlus softwares (WHO; Geneva, Switzerland).

Children were grouped according to their age into infants (0-2 years), PSAC (3-4 years), and SAC (5-10 years). According to $\mathrm{WHO}$ guidelines, moderate and severe malnutrition were defined at a MUAC cut-off of $12.5 \mathrm{~cm}$ and 
$11.5 \mathrm{~cm}$, respectively, for infants and PSAC [48,49]. Moderate and severe wasting were defined by applying a weight-for-height $\mathrm{z}$-score cut-off below -2 and -3 , respectively, for infants and PSAC and for combined sexes [49]. The weight-for-height of infants whose length was under $45 \mathrm{~cm}$ was not calculated. In the same age-group, moderate and severe underweight were defined at heightfor-age z-scores of -2 and -3 , respectively. For SAC, thinness and severe thinness were defined by a body mass index (BMI)-for-age z-score cut-off below -2 and -3, respectively, and stunting at a height-for-age z-score cut-off below -2 .

Anaemia thresholds were applied according to $\mathrm{WHO}$ recommendations as follows: haemoglobin values $>10.9 \mathrm{mg} / \mathrm{l}$ non-anaemia, 10.0-10.9 mg/l mild anaemia, 7.0-9.9 mg/l moderate anaemia, and $<7.0 \mathrm{mg} / \mathrm{l}$ severe anaemia for infants and PSAC, and haemoglobin values $>11.5 \mathrm{mg} / \mathrm{l}$ non-anaemia, 11.0-11.4 mg/l mild anaemia, 8.0-10.9 mg/l moderate anaemia, and $<8.0 \mathrm{mg} / \mathrm{l}$ severe anaemia for SAC [50]. Reference values for the full blood cell counts were taken from Buchanan and colleagues (2004) who provide haematology reference values for healthy Tanzanian children from the Kilimanjaro region stratified by age, including infants, PSAC, and SAC [51]. The cell counts of our children were classified as low, when they were below the 95\% confidence interval (CI) limit and as high when they were above the 95\% CI limit of the Kilimanjaro reference group. Fever was considered as axillary temperature of $>38.0^{\circ} \mathrm{C}$ as suggested by the Brighton Collaboration [52].

A patient was considered to be infected with a helminth species, if the infection was detected with one or several diagnostic methods. For each individual, helminth infection intensity was determined according to Kato-Katz thick smear results as suggested by the WHO [53]. For this purpose, faecal egg counts (FEC) as recorded from each Kato-Katz thick smear microscopic examination were transferred into eggs per gram of stool (EPG) by multiplying the average FEC from duplicate Kato-Katz thick smears of each individual by a factor 24 . The lower limits of moderate and heavy infections were 5,000 and 50,000 EPG for A. lumbricoides, 1,000 and 10,000 EPG for T. trichiura, 2,000 and 4,000 EPG for hookworm and 99 and 399 EPG for S. mansoni, respectively. Microhaematuria was classified according to the manufacturer's suggestion into negative, trace,,+++ , or +++ and $S$. haematobium egg counts into light (1-49 eggs $/ 10 \mathrm{ml}$ of urine) and heavy ( $\geq 50$ eggs/ $10 \mathrm{ml}$ of urine). Asymptomatic Plasmodium parasitaemia was defined by a positive malaria rapid diagnostic test result and/or by Plasmodium parasites detected microscopically plus the absence of unspecific symptoms of malaria at the day of enrolment or over the past seven days (i.e., fever, flue, cough, difficult breathing, and/or abdominal discomfort). Counts of below 10 parasites per 200 white blood cells (i.e. less than 400 parasites per $\mu \mathrm{l}$ blood) were defined as low grade parasitaemia, and counts of 100 and more parasites per 200 white blood cells (i.e. 400 or more parasites per $\mu$ l blood) as moderate parasitaemia.

To assess a direct interaction between helminth and helminth co-infections, and between helminth and asymptomatic Plasmodium parasitaemia co-infections we calculated observed and expected prevalences for co-infections [54]. The expected co-infection prevalences were calculated as the product of the observed prevalence of one infection (regardless of a co-infection) and the observed prevalence of the second infection (regardless of a coinfection). For comparison of the observed versus expected prevalences, the Fisher's exact test (two-sided) was applied.

Multivariable logistic regression analyses were used for estimating odds ratios (ORs), including 95\% CIs, to determine associations between different helminth species infections or asymptomatic Plasmodium parasitaemia or anaemia (binary outcome variables), and nutritional measures (ordinal or binary explanatory variable), anaemia (ordinal or binary explanatory variable), specific full blood cell count variables including haemoglobin (continuous explanatory variable), helminth co-infections (binary explanatory variable), asymptomatic Plasmodium parasitaemia (binary explanatory variable), temperature (continuous explanatory variable), or fever (binary explanatory variable). In all multivariable analyses we adjusted for age in months (continuous explanatory variable), sex (binary explanatory variable), and reported anthelmintic treatment in the past six months (binary explanatory variable) and included any significant explanatory variable from univariable models pertaining to the same outcome, excluding co-linear variables. For the multivariable logistic regression, we applied a backward stepwise procedure removing non-predicting covariates up to a significance level of 0.2 and allowed for possible clustering within houses by using the sandwich estimator robust cluster option in STATA. Both, univariable and multivariable regression analyses were run (i) for all ages and (ii) stratified by age-group.

\section{Results}

\section{Study group}

Written informed consent to participate in the crosssectional survey was provided for 1,033 children. Among them, 519 were girls and 514 were boys. According to their month and year of birth, 225 were grouped as infants, 336 as PSAC and 472 as SAC. The numbers of children with parasitological, haematological, and anthropometric examinations in each age-group are shown in Figure 1. 


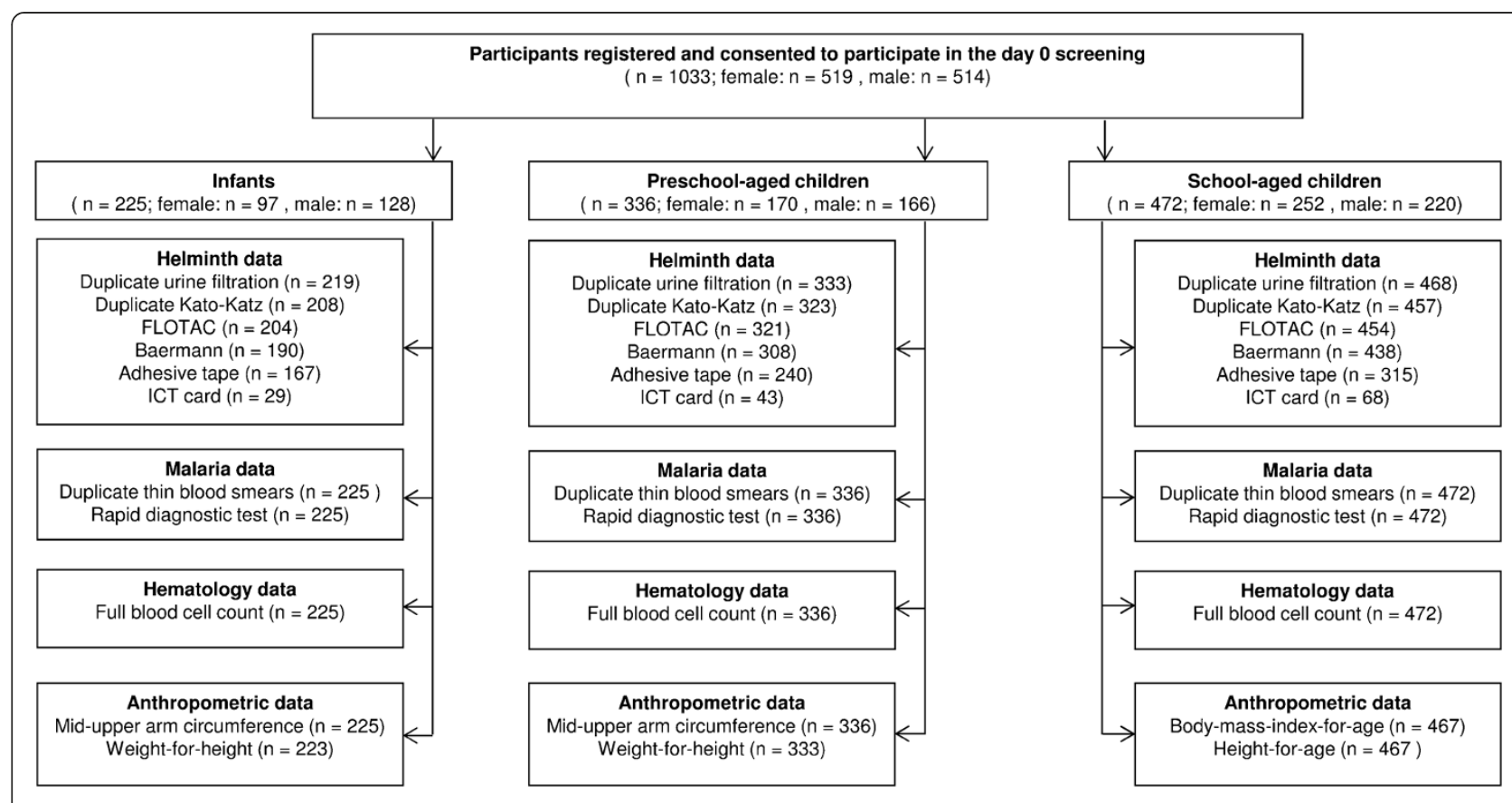

Figure 1 Characteristics of the IDEA-malaria study group consisting of children from the Bagamoyo district, United Republic of Tanzania.

\section{Anthropometric and haematological characteristics}

In our study group, $1.3 \%$ of infants were wasted and 2.2\% were underweight (Table 1). Among the PSAC, $0.3 \%$ were wasted and $2.4 \%$ were underweight. Thinness and stunting were detected in $3.2 \%$ and $18.7 \%$ of SAC, respectively. Anaemia was observed in $85.6 \%, 47.3 \%$, and $45.6 \%$ of infants, PSAC, and SAC, respectively.

As shown in Table 2, the full blood cell counts from children belonging to our study group revealed that more than $70 \%$ of the children had haematocrit, mean corpuscular volume, platelets, white blood cell counts, neutrophil and lymphocyte counts within the normal range, when compared to haematological reference values derived from children of the same age-groups residing in the Kilimanjaro district, United Republic of Tanzania [51]. However, more than $10 \%$ of our children in any age-group had elevated white blood cell and lymphocyte counts and more than $20 \%$ had high neutrophil counts. High monocyte, eosinophil and basophil counts were detected in more than $30 \%$ of our children regardless of age-group.

\section{Parasitic infections, fever, and microhaematuria}

Among all children examined for helminth infections, E. vermicularis was found in $18.0 \%$, hookworm in $9.1 \%$, S. stercoralis in $6.9 \%, T$. trichiura in $2.5 \%, W$. bancrofti in $1.4 \%$, S. haematobium in $0.3 \%$, and A. lumbricoides in $0.1 \%$. No child was diagnosed with a S. mansoni infection.

Stratified by age-group, infections with any investigated helminth species were found in $10.2 \%$ of infants, $25.0 \%$ of
PSAC, and 33.5\% of SAC. As shown in Figure 2, the most prevalent helminth infections in infants were with S. stercoralis (5.8\%) and E. vermicularis (4.2\%), followed by W. bancrofti (3.4\%), hookworm (2.5\%), and T. trichiura (0.5\%). The youngest children infected with T. trichiura, W. bancrofti, S. stercoralis, E. vermicularis, and hookworms were aged six, seven, ten, eleven, and 15 months, respectively. PSAC and SAC were mostly infected with E. vermicularis ( $16.7 \%$ and $26.3 \%$, respectively), hookworm (8.7\% and $12.3 \%$, respectively), S. stercoralis (7.5\% and $7.1 \%$, respectively), and T. trichiura $(2.5 \%$ and $3.3 \%$, respectively).

Among the 70 children diagnosed with a hookworm infection by the Kato-Katz method, 60 (85.7\%) showed a light, $6(8.6 \%)$ a moderate, and $4(5.7 \%)$ a heavy infection intensity. Among the 21 T. trichiura positive children, 19 (90.5\%) had a light and 2 (9.5\%) a moderate infection intensity. The only child infected with $A$. lumbricoides had a moderate infection intensity. All three children infected with $S$. haematobium had light infection intensities.

Asymptomatic Plasmodium parasitaemia was diagnosed in $7.6 \%$ of infants, $9.8 \%$ of PSAC, and $18.9 \%$ of SAC, respectively. Among all children with asymptomatic Plasmodium parasitaemia, $66.3 \%$ had a moderate parasitaemia and $33.7 \%$ had a low parasitaemia. Fever at the day of examination was measured in $1.3 \%$ of infants and $0.6 \%$ of SAC without Plasmodium parasitaemia. Microhaematuria was detected in $10.5 \%$ of infants, $3.9 \%$ of PSAC, and $2.4 \%$ of SAC, respectively. 
Table 1 Anthropometric and anaemia status of infants, preschool-aged (PSAC), and school-aged children (SAC) from the Bagamoyo district, United Republic of Tanzania, calculated in line with guidelines and thresholds provided by the World Health Organization [48-50]

\begin{tabular}{|c|c|c|c|c|c|c|c|c|c|}
\hline \multirow[b]{3}{*}{ Anthropometric aspects } & \multicolumn{9}{|c|}{ Age group } \\
\hline & \multicolumn{3}{|c|}{ Infants } & \multicolumn{3}{|l|}{ PSAC } & \multicolumn{3}{|l|}{ SAC } \\
\hline & Total & $\mathrm{n}$ & $\%$ & Total & $\mathrm{n}$ & $\%$ & Total & $\mathrm{n}$ & $\%$ \\
\hline Mid-upper arm circumference & 225 & & & 336 & & & & & \\
\hline Normal & & 222 & 98.7 & & 335 & 99.7 & & & \\
\hline Moderately wasted & & 3 & 1.3 & & 1 & 0.3 & & & \\
\hline Severely wasted & & 0 & 0 & & 0 & 0 & & & \\
\hline Weight-for-height & 223 & & & 333 & & & & & \\
\hline Normal & & 218 & 97.8 & & 325 & 97.6 & & & \\
\hline Moderate underweight & & 2 & 0.9 & & 7 & 2.1 & & & \\
\hline Severe underweight & & 3 & 1.3 & & 1 & 0.3 & & & \\
\hline Body-mass-index-for-age & & & & & & & 467 & & \\
\hline Normal & & & & & & & & 452 & 96.8 \\
\hline Moderate thinness & & & & & & & & 10 & 2.1 \\
\hline Severe thinness & & & & & & & & 5 & 1.1 \\
\hline Height-for-age & & & & & & & 467 & & \\
\hline Normal & & & & & & & & 380 & 81.4 \\
\hline Moderate stunting & & & & & & & & 68 & 14.6 \\
\hline Severe stunting & & & & & & & & 19 & 4.1 \\
\hline Anaemia & 221 & & & 334 & & & 471 & & \\
\hline Normal & & 32 & 14.5 & & 176 & 52.7 & & 256 & 54.4 \\
\hline Mild anaemia & & 74 & 33.5 & & 108 & 32.3 & & 81 & 17.2 \\
\hline Moderate anaemia & & 106 & 48.0 & & 47 & 14.1 & & 127 & 27.0 \\
\hline Severe anaemia & & 9 & 4.1 & & 3 & 0.9 & & 7 & 1.5 \\
\hline
\end{tabular}

Comparison between observed and expected co-infection prevalences

A summary of observed versus expected parasite coinfection prevalences is presented in Table 3. Significant differences in prevalence, suggestive for non-chance findings, were detected for co-infection with S. stercoralis and asymptomatic Plasmodium parasitaemia in children of all age-groups $(\mathrm{p}=0.039)$, but particularly in infants $(\mathrm{p}=$ 0.006). Moreover, observed co-infections with S. stercoralis and hookworm in all age-groups $(\mathrm{p}=0.038)$, S. stercoralis and $T$. trichiura in all age-groups $(\mathrm{p}=0.018)$, but particularly in SAC $(\mathrm{p}=0.016)$, and hookworm and T. trichiura in all age-groups $(\mathrm{p}=0.004)$, but particularly in PSAC $(\mathrm{p}=0.022)$ were significantly higher than expected by chance.

Association of helminth infections with anthropometric measures, haematology, and parasitic co-infections Results of the multivariable regression models stratified by helminth infection and age-group are shown in detail in Table 4. After adjusting for potential confounders in multivariable analyses and here only presenting OR higher than 2.00, strongyloidiasis was associated with asymptomatic Plasmodium parasitaemia in infants (S. stercoralis as outcome: OR: 13.03; 95\% CI: 1.34 - 127.23; asymptomatic Plasmodium parasitaemia as outcome: OR: 5.75; 95\% CI: 1.21 - 27.41). Elevated eosinophil counts in infants were a predictor for S. stercoralis (OR: 4.00; 95\% CI: 1.10 - 14.58) and hookworm infections (OR: 16.60; CI: 1.39 - 198.32). Infants with a reported anthelmintic treatment in the past 6 months were more likely to be infected with hookworm (OR: 27.91; 95\% CI: 5.52 - 141.21).

Preschool-aged children with increased temperature had higher odds of presenting with a hookworm infection (OR: 3.74; 95\% CI: 1.14 - 12.28). Hookworm and T. trichiura infections were positively associated in this age-group (hookworm as outcome OR: 22.78\%; 95\% CI: 4.43 - 117.23; T. trichiura as outcome OR: 11.53 ; 95\% CI: 2.30 - 57.77). Elevated monocyte counts were a predictor for asymptomatic Plasmodium parasitaemia in PSAC (OR: 13.88; 95\% CI 3.42 - 56.30).

School-aged children with S. stercoralis infection had higher odds of being co-infected with T. trichiura (OR: 6.63; 95\% CI: 1.52 - 28.93). In this age-group, children 
Table 2 Haematological values derived from full blood cell counts from infants, preschool-aged (PSAC), and school-aged children (SAC) from the Bagamoyo district, United Republic of Tanzania

\begin{tabular}{|c|c|c|c|c|c|c|c|c|c|}
\hline \multirow[t]{2}{*}{ Age group } & \multicolumn{3}{|c|}{ Infants } & \multicolumn{3}{|l|}{ PSAC } & \multicolumn{3}{|l|}{ SAC } \\
\hline & Total & $\mathrm{n}$ & $\%$ & Total & $\mathrm{n}$ & $\%$ & Total & $\mathrm{n}$ & $\%$ \\
\hline Haematocrit (\%) & 225 & & & 336 & & & 472 & & \\
\hline Low & & 12 & 5.3 & & 5 & 1.5 & & 60 & 12. \\
\hline Normal & & 190 & 84.4 & & 305 & 90.8 & & 372 & 78 \\
\hline High & & 23 & 10.2 & & 26 & 7.7 & & 40 & 8.5 \\
\hline
\end{tabular}

Mean corpuscular volume (pg) 225

Low
Normal
High

Platelets $\left(10^{9} / \mathrm{l}\right)$

Low

Normal

High

White blood cells $\left(10^{9} / \mathrm{l}\right)$

Low

Normal

High

Neutrophils $\left(10^{9} / \mathrm{I}\right)$

Low

Normal

High

Lymphocytes $\left(10^{9} / \mathrm{I}\right)$

Low

Normal

High

Monocytes $\left(10^{9} / \mathrm{I}\right)$

Low

Normal

High

Eosinophils $\left(10^{9} / \mathrm{I}\right)$

Low

Normal

High

Basophils $\left(10^{9} / \mathrm{I}\right)$

Low

Normal

High

Reference values are derived from children living in the Kilimanjaro district [51].

presenting with increased temperature were more likely to be infected with E. vermicularis (OR: 2.21; 95\% CI: 1.13 - 4.33). Increased eosinophil counts were predictors for infections with $T$. trichiura, hookworm, and S. stercoralis (OR: 3.23; 95\% CI: 1.73 - 6.02, OR: 2.71; 95\% CI: 1.39 5.31; and OR: 2.15; 95\% CI: 1.10 - 14.58, respectively).
336

$\begin{array}{ll}19 & 8.4 \\ 186 & 82.7 \\ 20 & 8.9\end{array}$

225

$\begin{array}{ll}1 & 0.4 \\ 202 & 89.8 \\ 22 & 9.8\end{array}$

225

$\begin{array}{ll}0 & 0.0 \\ 182 & 80.9 \\ 43 & 19.1\end{array}$

225

$\begin{array}{ll}2 & 0.9 \\ 176 & 78.2 \\ 47 & 20.9\end{array}$

225

$\begin{array}{ll}6 & 2.7 \\ 183 & 81.3 \\ 36 & 16.0\end{array}$

225

$\begin{array}{ll}0 & 0.0 \\ 114 & 50.7 \\ 111 & 49.3\end{array}$

225

$\begin{array}{ll}11 & 4.9 \\ 127 & 56.4 \\ 87 & 38.7\end{array}$

225

$2 \quad 0.9$

$143 \quad 63.6$

$80 \quad 35.6$

336

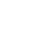

$x^{2}$

336

336

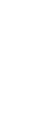

336

336

336

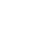

336

336

.

$\begin{array}{ll}2 & 0.6 \\ 308 & 91.7 \\ 26 & 7.7\end{array}$

$\begin{array}{ll}5 & 1.5 \\ 305 & 90.8 \\ 26 & 7.7\end{array}$

472

$\begin{array}{ll}28 & 5.9 \\ 408 & 86.4 \\ 36 & 7.6\end{array}$

472

$\begin{array}{ll}15 & 3.2 \\ 420 & 89.0 \\ 37 & 7.8\end{array}$

472

$\begin{array}{ll}0 & 0.0 \\ 288 & 85.7 \\ 48 & 14.3\end{array}$

472

$\begin{array}{ll}4 & 0.8\end{array}$

$\begin{array}{ll}0 & 0.0 \\ 266 & 79.2 \\ 70 & 20.8\end{array}$

351

$\begin{array}{ll}6 & 1.3 \\ 350 & 74.2 \\ 116 & 24.6\end{array}$

$\begin{array}{ll}6 & 1.8 \\ 292 & 86.9 \\ 38 & 11.3\end{array}$

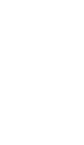

$\begin{array}{ll}0 & 0.0 \\ 198 & 58.9 \\ 138 & 41.1\end{array}$

3.6

$\begin{array}{ll}12 & 3.6 \\ 187 & 55.7 \\ 137 & 40.8\end{array}$

336

\begin{tabular}{ll}
0 & 0.0 \\
221 & 65.8 \\
115 & 34.2 \\
\hline
\end{tabular}

472

472

472

472

$\begin{array}{ll}249 & 52.8\end{array}$

$223 \quad 47.2$

47.

$\begin{array}{ll}12 & 2.5 \\ 276 & 58.5 \\ 184 & 39.0\end{array}$

Grouping children according to WHO anaemia thresholds, in children below the age of two years asymptomatic Plasmodium parasitaemia was associated with light (OR: 1.84; 95\% CI 1.04 - 3.27), moderate (OR: 5.36; 95\% CI 2.92 - 9.82), or severe anaemia (OR: 11.20; 4.20 - 29.86). Also children aged older than two years presenting with 




moderate (OR: 3.07; 95\% CI 1.96 - 4.81) or severe anaemia (OR: 7.27; 95\% CI 2.04 - 25.96) were more likely to have an asymptomatic Plasmodium parasitaemia. In turn, children in the latter age-range presenting with moderate asymptomatic Plasmodium parasitaemia were more likely to be anaemic (OR: 2.69; 95\% CI: 1.23 - 5.86).

Wasting, underweight, stunting, thinness, fever and microhaematuria were not associated with any helminth infection, asymptomatic Plasmodium parasitaemia or anaemia in our study population.

\section{Discussion}

Little is known about the epidemiology and public health importance of S. stercoralis and E. vermicularis infections in Sub-Saharan Africa. We found that strongyloidiasis and enterobiasis were predominant to other helminthiases in our study population. Noteworthy, already infants, an age-group mostly ignored in studies pertaining to soiltransmitted helminthiases, presented with S. stercoralis (5.8\%) and E. vermicularis infections (4.2\%). Prevalences increased with age, and $7.5 \%$ and $7.1 \%$ of PSAC and SAC, respectively, were infected with S. stercoralis and $16.7 \%$ and $26.3 \%$, respectively, with $E$. vermicularis.

The prevalences for all helminth infections determined in our study population are relatively low compared to those reported from other settings in the United Republic of Tanzania $[36,55,56]$. The following considerations are offered for explanation: Firstly, over the past decade, Tanzania has successfully implemented a series of helminth control interventions $[57,58]$, which might have reduced the infections in the population. Indeed, our under five year old children might have received Mebendazole in the frame of the biannual interventions of the Expanded Programme on Immunisation (EPI), which provides vitamin A supplementation, measles vaccination, and deworming in the Bagamoyo District, and the SAC might have been targeted by school-based deworming organized by the Ministry of Health. Secondly, we included infants, PSAC, and SAC aged two months to ten years in our study. The age-prevalence-curve for the major soil-transmitted helminth infections and schistosomiasis increases with age and peaks in children between 8 and 15 years [3,59]. Our children were hence not yet in the peak age for infection, but an increase in the prevalence of all investigated helminth species with age was indeed observed. Thirdly, the conventional parasitological diagnostic methods that we applied lack sensitivity, particularly when infection intensities are low and only a single faecal sample is examined $[9,60,61]$. While we used duplicate Kato-Katz thick smears and the FLOTAC dual technique on a single stool sample to detect soil-transmitted helminth and S. mansoni infections and duplicate urine filtrations from a single urine for $S$. haematobium diagnosis, the true helminth prevalences in our study were likely considerably higher.

S. stercoralis infections were associated with eosinophilia in our study population, a condition that is generally attributed to strongyloidiasis [13,17]. Our study also confirmed results from the neighbouring Zanzibar island with regard to a positive association between S. stercoralis and $T$. trichiura infections [55]. Novel is our finding that strongyloidiasis was associated with asymptomatic 
Table 3 Infants', preschool-aged children's (PSAC) and school-aged children's (SAC) co-infection status with hookworm, S. stercoralis, E. vermicularis, T. trichiura, and/or asymptomatic Plasmodium parasitaemia in the Bagamoyo region, United Republic of Tanzania, and comparison between observed and expected co-infection prevalence at the unit of age-group

\begin{tabular}{|c|c|c|c|c|}
\hline & Examined children $(\mathrm{n})$ & Observed co-infection (\%) & Expected co-infection (\%)* & P-val \\
\hline \multicolumn{5}{|c|}{ Asymptomatic Plasmodium and E. vermicularis infection } \\
\hline Infants & 167 & 0.60 & 0.30 & 0.413 \\
\hline PSAC & 240 & 1.67 & 1.46 & 0.760 \\
\hline SAC & 315 & 5.71 & 5.44 & 0.7 \\
\hline All age-groups & 722 & 3.19 & 2.44 & 0.1 \\
\hline
\end{tabular}

Asymptomatic Plasmodium and hookworm infection

$\begin{array}{lllll}\text { Infants } & 204 & 0.49 & 0.19 & 0.338 \\ \text { PSAC } & 322 & 0.93 & 0.86 & 0.749 \\ \text { SAC } & 454 & 2.42 & 2.28 & 0.854 \\ \text { All age-groups } & 980 & 1.53 & 1.22 & 0.329\end{array}$

Asymptomatic Plasmodium and S. stercoralis infection

$\begin{array}{lll}\text { Infants } & 190 & 2.1 \\ \text { PSAC } & 308 & 0.97 \\ \text { SAC } & 438 & 1.83 \\ \text { All age-groups } & 936 & 1.60\end{array}$

2.11

1.60

Asymptomatic Plasmodium and T. trichiura infection

Infants 204

PSAC $\quad 321$

SAC $\quad 454$

All age-groups

979

Hookworm and $E$. vermicularis infection

Infants

155

PSAC

229

SAC

305

All age-groups

689

Hookworm and S. stercoralis infection

$\begin{array}{ll}\text { Infants } & 188 \\ \text { PSAC } & 307 \\ \text { SAC } & 436 \\ \text { All age-groups } & 931\end{array}$

Hookworm and T. trichiura infection

Infants

204

PSAC

321

SAC

454

All age-groups

979

S. stercoralis and E. vermicularis infection

Infants

144

PSAC

215

SAC

292

All age-groups

651

S. stercoralis and T. trichiura infection

Infants

0.00

0.00

0.44

0.20

0.65

2.18

3.61

2.47

0.53

0.98

1.61

1.18

0.00

0.93

0.88

0.72

0.00

1.40

1.37

1.08

0.00

\subsection{6}

0.75

1.36

0.96

0.04

0.25

0.61

0.33

0.12

1.93 
Table 3 Infants', preschool-aged children's (PSAC) and school-aged children's (SAC) co-infection status with hookworm, S. stercoralis, E. vermicularis, T. trichiura, and/or asymptomatic Plasmodium parasitaemia in the Bagamoyo region, United Republic of Tanzania, and comparison between observed and expected co-infection prevalence at the unit of age-group (Continued)

\begin{tabular}{|c|c|c|c|c|}
\hline PSAC & 307 & 0.33 & 0.17 & 0.423 \\
\hline SAC & 436 & 0.92 & 0.24 & 0.016 \\
\hline All age-groups & 931 & 0.54 & 0.17 & 0.018 \\
\hline \multicolumn{5}{|c|}{ E. vermicularis and $T$. trichiura infection } \\
\hline Infants & 155 & 0.00 & 0.02 & 1.000 \\
\hline PSAC & 228 & 0.44 & 0.53 & 1.000 \\
\hline SAC & 305 & 1.31 & 0.93 & 0.484 \\
\hline All age-groups & 688 & 0.73 & 0.50 & 0.361 \\
\hline
\end{tabular}

*Expected co-infection prevalence is the product of the observed infection prevalence of one species (regardless of a co-infection) and the observed infection prevalence of the other species (irrespective of co-infection).

**Comparison of observed and expected co-infection proportions, p-value based on a Fisher's Exact-test.

Plasmodium parasitaemia in infants. While the expected prevalence of this co-infection in infants was only $0.5 \%$, the observed prevalence was $2.1 \%$. However, due to the very low number of co-infected infants and multiple testing, these findings must be interpreted with care. If future studies with a larger number of co-infected children confirm our results, it might be reasonable to assume that this tissue invasive helminth species in particular is modulating immunological pathways related to the acquisition, replication, and pathologic sequelae of Plasmodium infections. In the worst case, $S$. stercoralis infections in infants may be a contributing factor to the delayed acquisition of clinical immunity to malaria in this highly vulnerable age-group. More indepth-studies on the immunological interplay of strongyloidiasis and malaria are clearly needed.

To date, leading reviews on the global distribution and risk factors for S. stercoralis do not mention malaria, and publications summarizing the epidemiology and immunological interplay of helminth and malaria co-infection ignore S. stercoralis, respectively. The only study we found assessing S. stercoralis infections and malaria was on pregnant women from Uganda, and revealed no association [62]. Moreover, there are only very few publications mentioning S. stercoralis infections in infants and PSAC in sub-Saharan Africa, and there are no recent reports assessing strongyloidiasis in any age-group on mainland Tanzania $[10,19,63-65]$. Our findings that $S$. stercoralis was infecting a considerable number of young children of our study population from the age of ten months onwards, and was associated with asymptomatic Plasmodium parasitaemia, underline the importance of diagnosing this disease. Inclusion of S. stercoralis into helminth control programs, as suggested by other research teams, needs to be considered [7,19,21].

Enterobiasis was not associated with any specific haematological marker or helminth co-infection, but children of all age-groups with a reported anthelminthic treatment history over the past six months and SAC with an increased temperature had higher odds of an infection. This finding suggests that children with enterobiasis suffer, likely from anal itching and ill-being, and sought treatment for relief. The higher odds of infection might be a sign that either the treatment as administered did not cure the infection or that children got rapidly reinfected, likely due to transmission from additional infected family members [25]. Similarly, infants with reported anthelminthic treatment history had higher odds of hookworm infection in our study. Also hookworm infection can considerably impact on a child's health and wellbeing [10] and therefore treatment might have been sought. However, infants with hookworm infection who had a reported treatment history might either not have been cured by the treatment or live in a particularly unhygienic environment that favours rapid reinfection. Cure might not have been achieved since, in case mebendazole was administered, cure rates for hookworm are very low [66] or, in case no liquid formulation was available, crushed tablets were difficult to administer to very young children and might not have resulted in complete clearance of infection.

Neither E. vermicularis nor hookworm infection was associated with asymptomatic Plasmodium parasitaemia in our study. While there are hardly any cross-sectional surveys assessing $E$. vermicularis infections with appropriate diagnostic methods in sub-Saharan Africa, let alone its potential association with malaria, there are multiple studies investigating associations between hookworm and Plasmodium infections. In line with our findings, there are studies that did not find an association between hookworm and Plasmodium infections $[67,68]$. Other studies, however, indicate significant associations between these infectious diseases $[38,62,69]$. The heterogeneous results and potential consequences of co-infections are nicely summarized in recent reviews $[27,28]$. 
Table 4 Helminth infections and significantly associated factors according to stepwise backwards multivariable regression analyses in infants, preschool-aged (PSAC), and school-aged children (SAC) from the Bagamoyo district, United Republic of Tanzania

\begin{tabular}{|c|c|c|c|c|c|c|c|}
\hline Helminth infection & Age-group & Explanatory variable & $\mathbf{n}$ & OR & 95\% Confidence interval & p-value & Original model run with* \\
\hline \multirow[t]{13}{*}{ E. vermicularis } & all age-groups & Gender & 585 & 0.70 & $(0.45-1.11)$ & 0.127 & $9,1,2,3,4,6,7,16,17,20$ \\
\hline & & Age (month) & & 1.03 & $(1.02-1.05)$ & $<0.001$ & \\
\hline & & Temperature & & 1.60 & $(0.96-2.67)$ & 0.071 & \\
\hline & & Weight & & 0.91 & $(0.82-1.00)$ & 0.051 & \\
\hline & & Anthelmintic treatment & & 2.15 & $(1.22-3.79)$ & 0.008 & \\
\hline & & Neutrophil counts & & 1.10 & $(1.01-1.20)$ & 0.034 & \\
\hline & Infants & Gender & 158 & 3.72 & $(0.68-20.36)$ & 0.129 & $9,1,2,3,21$ \\
\hline & & Age (month) & & 1.13 & $(1.01-1.27)$ & 0.027 & \\
\hline & PSAC & Gender & 201 & 0.51 & $(0.23-1.16)$ & 0.108 & $9,1,2,3,16$ \\
\hline & & Anthelmintic treatment & & 3.60 & $(1.01-12.86)$ & 0.049 & \\
\hline & & Neutrophil counts & & 1.09 & $(1.00-1.19)$ & 0.041 & \\
\hline & SAC & Temperature & 315 & 2.21 & $(1.13-4.33)$ & 0.021 & $9,1,2,3,4$ \\
\hline & & Anthelmintic treatment & & 1.78 & $(0.94-3.36)$ & 0.076 & \\
\hline \multirow[t]{14}{*}{ S. stercoralis } & all age-groups & Gender & 624 & 0.62 & $(0.32-1.21)$ & 0.163 & $11,1,2,3,4,10,12,13,14,19$ \\
\hline & & Anthelmintic treatment & & 1.65 & $(0.80-3.41)$ & 0.178 & \\
\hline & & T. trichiura & & 4.13 & $(1.04-16.52)$ & 0.045 & \\
\hline & & $\begin{array}{l}\text { Asymptomatic Plasmodium } \\
\text { parasitaemia }\end{array}$ & & 2.10 & $(0.97-4.51)$ & 0.058 & \\
\hline & & Eosinophil counts & & 2.04 & $(1.20-3.48)$ & 0.008 & \\
\hline & & Platelet counts & & 1.00 & $(0.99-1.00)$ & 0.064 & \\
\hline & Infants & Gender & 132 & 0.13 & $(0.01-1.38)$ & 0.091 & $11,1,2,3,6,7,13,14$ \\
\hline & & Age (month) & & 1.20 & $(0.97-1.49)$ & 0.086 & \\
\hline & & $\begin{array}{l}\text { Asymptomatic Plasmodium } \\
\text { parasitaemia }\end{array}$ & & 13.03 & $(1.34-127.23)$ & 0.027 & \\
\hline & & Eosinophil counts & & 4.00 & $(1.10-14.58)$ & 0.036 & \\
\hline & PSAC & Light anaemia & 303 & 0.19 & $(0.04-0.82)$ & 0.026 & $11,1,2,3,21$ \\
\hline & SAC & T. trichiura & 290 & 3.59 & $(0.80-16.08)$ & 0.095 & $11,1,2,3,4,12,14,19$ \\
\hline & & Eosinophil counts & & 2.15 & $(1.10-4.23)$ & 0.026 & \\
\hline & & Platelet counts & & 0.99 & $(0.98-1.00)$ & 0.011 & \\
\hline \multirow[t]{14}{*}{ Hookworm } & all age-groups & Temperature & 623 & 1.77 & $(0.83-3.78)$ & 0.143 & $10,1,2,3,4,6,7,11,12,14,16,20$ \\
\hline & & Weight & & 1.12 & $(1.05-1.18)$ & $<0.001$ & \\
\hline & & T. trichiura & & 3.33 & $(0.77-14.39)$ & 0.107 & \\
\hline & & Eosinophil counts & & 2.30 & $(1.29-4.09)$ & 0.005 & \\
\hline & Infants & Anthelmintic treatment & 138 & 27.91 & $(5.52-141.21)$ & $<0.001$ & $10,1,2,3,6,7,14,16,20$ \\
\hline & & Eosinophil counts & & 16.60 & $(1.39-198.32)$ & 0.026 & \\
\hline & & Basophil counts & & 0.10 & $(0.01-0.86)$ & 0.036 & \\
\hline & & Haemoglobin & & 1.96 & $(1.13-3.41)$ & 0.016 & \\
\hline & PSAC & Gender & 272 & 1.97 & $(0.72-5.38)$ & 0.185 & $10,1,2,3,4,12,16$ \\
\hline & & Temperature & & 3.74 & $(1.14-12.28)$ & 0.030 & \\
\hline & & Anthelmintic treatment & & 0.52 & $(0.2-1.34)$ & 0.174 & \\
\hline & & T. trichiura & & 22.78 & $(4.43-117.23)$ & $<0.001$ & \\
\hline & & Neutrophil counts & & 1.11 & $(1.01-1.21)$ & 0.03 & \\
\hline & SAC & Eosinophil counts & 295 & 2.71 & $(1.39-5.31)$ & 0.004 & $10,1,2,3,14,27$ \\
\hline
\end{tabular}


Table 4 Helminth infections and significantly associated factors according to stepwise backwards multivariable regression analyses in infants, preschool-aged (PSAC), and school-aged children (SAC) from the Bagamoyo district, United Republic of Tanzania (Continued)

\begin{tabular}{|c|c|c|c|c|c|c|c|}
\hline \multirow[t]{10}{*}{ T. trichiura } & \multirow[t]{4}{*}{ all age-groups } & Anthelmintic treatment & \multirow[t]{4}{*}{623} & 0.12 & $(0.03-0.54)$ & 0.005 & \multirow[t]{4}{*}{$12,1,2,3,11,14,18$} \\
\hline & & S. stercoralis & & 5.18 & $(1.45-18.46)$ & 0.011 & \\
\hline & & Eosinophil counts & & 3.28 & $(1.69-6.36)$ & 0.001 & \\
\hline & & Monocyte counts & & 0.02 & $(0.00-0.33)$ & 0.007 & \\
\hline & Infants & Age (month) & 55 & 0.51 & $(0.31-0.85)$ & 0.009 & $12,1,2,3$ \\
\hline & \multirow[t]{2}{*}{ PSAC } & Hookworm & \multirow[t]{2}{*}{297} & 11.53 & $(2.30-57.77)$ & 0.003 & \multirow[t]{2}{*}{$12,1,2,3,10,19$} \\
\hline & & Platelet counts & & 1.01 & $(1.00-1.01)$ & 0.008 & \\
\hline & \multirow[t]{3}{*}{ SAC } & Anthelmintic treatment & \multirow[t]{3}{*}{290} & 0.08 & $(0.01-0.48)$ & 0.006 & \multirow[t]{3}{*}{$12,1,2,3,6,11,14$} \\
\hline & & S. stercoralis & & 6.63 & $(1.52-28.93)$ & 0.012 & \\
\hline & & Eosinophil counts & & 3.23 & $(1.73-6.02)$ & 0.001 & \\
\hline \multirow[t]{15}{*}{ Plasmodium parasitaemia } & \multirow[t]{4}{*}{ all age-groups } & Age (month) & \multirow[t]{4}{*}{952} & 1.03 & $(1.02-1.04)$ & $<0.001$ & \multirow[t]{4}{*}{$13,1,2,3,6,7,19,20$} \\
\hline & & Anthelmintic treatment & & 0.73 & $(0.49-1.10)$ & 0.137 & \\
\hline & & Haemoglobin & & 0.65 & $(0.56-0.76)$ & $<0.001$ & \\
\hline & & Platelet counts & & 1.00 & $(0.99-1.00)$ & 0.012 & \\
\hline & \multirow[t]{4}{*}{ Infants } & Gender & \multirow[t]{4}{*}{177} & 2.88 & $(0.79-10.55)$ & 0.111 & \multirow[t]{4}{*}{$13,1,2,3,6,7,11,19$} \\
\hline & & Weight & & 1.39 & $(0.97-1.99)$ & 0.071 & \\
\hline & & S. stercoralis & & 5.75 & $(1.21-27.41)$ & 0.028 & \\
\hline & & Platelet counts & & 0.99 & $(0.99-1.00)$ & 0.022 & \\
\hline & \multirow[t]{3}{*}{ PSAC } & Weight & \multirow[t]{3}{*}{230} & 1.27 & $(1.06-1.52)$ & 0.010 & \multirow[t]{3}{*}{$13,1,2,3,7,18,20$} \\
\hline & & Haemoglobin & & 0.49 & $(0.34-0.73)$ & $<0.001$ & \\
\hline & & Monocyte counts & & 13.88 & $(3.42-56.30)$ & $<0.001$ & \\
\hline & \multirow[t]{4}{*}{ SAC } & Age (month) & \multirow[t]{4}{*}{312} & 1.03 & $(1.01-1.05)$ & 0.004 & \multirow[t]{4}{*}{$13,1,2,3,18,20$} \\
\hline & & Anthelmintic treatment & & 0.65 & $(0.36-1.19)$ & 0.161 & \\
\hline & & Haemoglobin & & 0.69 & $(0.53-0.90)$ & 0.007 & \\
\hline & & Monocyte counts & & 2.54 & $(0.77-8.37)$ & 0.126 & \\
\hline \multirow[t]{10}{*}{ Plasmodium parasitaemia } & \multirow[t]{5}{*}{$<2$ years } & Light anaemia & \multirow[t]{5}{*}{625} & 1.84 & $(1.04-3.27)$ & 0.037 & \multirow[t]{5}{*}{$13,1,2,3,21$} \\
\hline & & Moderate anaemia & & 5.36 & $(2.92-9.82)$ & $<0.001$ & \\
\hline & & Severe anaemia & & 11.20 & $(4.20-29.86)$ & $<0.001$ & \\
\hline & & Age (month) & & 1.04 & $(1.025-1.05)$ & $<0.001$ & \\
\hline & & Anthelmintic treatment & & 0.72 & $(0.47-1.10)$ & 0.129 & \\
\hline & \multirow[t]{5}{*}{$>2$ years } & Light anaemia & 537 & 1.57 & $(0.88-2.78)$ & 0.123 & $13,1,2,3,21$ \\
\hline & & Moderate anaemia & & 3.07 & $(1.96-4.81)$ & $<0.001$ & \\
\hline & & Severe anaemia & & 7.27 & $(2.04-25.96)$ & 0.002 & \\
\hline & & Gender & & 0.70 & $(0.47-1.04)$ & 0.076 & \\
\hline & & Age (month) & & 1.02 & $(1.00-1.03)$ & 0.021 & \\
\hline
\end{tabular}

*Explanatory variables with significant outcome in the univariable analysis and included in the original model of the multivariate analysis 1: Gender; 2: Age (month); 3 : Anthelmintic treatment; 4: Temperature; 5: mid-upper arm circumference (MUAC); 6: Height; 7: Weight; 8: A. lumbricoides infection; 9: E. vermicularis infection; 10: Hookworm infection; 11: S. stercoralis infection; 12: T. trichiura infection; 13: Asymptomatic Plasmodium parasitaemia; 14: Eosinophil counts; 15: Basophil counts; 16: Neutrophil counts; 17: Lymphocyte counts; 18: Monocyte counts; 19: Platelet counts; 20: Haemoglobin; 21: Anaemia; 22: Malnutrition; 23: Stunting; 24: Thinness; 25: Underweight; 26: Wasting; 27: Fever.

The table shows the significant explanatory variables that remained in the final model with $\mathrm{p}<0.2$.

Neither S. stercoralis, E. vermicularis, hookworm, nor any other investigated helminth infection was associated with wasting, underweight, thinness, stunting, or anaemia in our study population. While wasting, underweight, and thinness were rarely seen in the surveyed children and therefore no association could be determined, stunting occurred in $18.5 \%$ of SAC and anaemia affected more than half of the examined children. Previous studies 
conducted in the Kilombero district in Tanzania in the early 1980s had also revealed no association between wasting or stunting and intestinal helminth infection or Plasmodium parasitaemia [65]. In that particular time and place the observed substantial differences in the nutritional status of children were related to the lean and post-harvest seasons [70,71]. The Bagamoyo district, however, is relatively rich in cash-crop production agricultural systems throughout the year, and was one of the four councils in Tanzania, that were not reported to have major food and nutrition insecurity problems in 2011/12 [72]. This might explain why no acute but only chronic signs of malnutrition like stunting were found in our study. Other studies indicated that particularly moderate-to-heavy intensity helminth infections were associated with reduced length-for-age $\mathrm{z}$-score in young infected children from Peru [73], with decreased weight-for-age z-scores in SAC from Honduras [74], and with stunting in SAC from China [75]. The occurrence of mostly light helminth infection intensities in our study might hence explain why no association was found.

Anaemia was related with asymptomatic Plasmodium parasitaemia but not with helminthiases in infants, PSAC, and SAC in our study. It is widely acknowledged that Plasmodium infections, also if low-grade and asymptomatic as a result of semi-immunity, contribute to the development of anaemia [76]. Also hookworm infections have been shown to contribute to anaemia, particularly in children and women of childbearing age, and when infection intensities were moderate-to-heavy [3,77-80]. Also here, the reason for not finding any association of helminth infections with anaemia might be due to the mostly light infection intensities found in our study population. Clearly, the low prevalence of helminth infections and specifically of moderate and high infection intensities, resulting in a lack of statistical power to determine effects on nutritional aspects including anaemia and stunting, are a limitation of this study. Moreover, we did not assess additional reasons for malnutrition and anaemia, such as restricted access to micro-nutrients, agricultural and dietary practices, food security, or social, political, and economic determinants, which might have biased our results.

Elevated eosinophil counts were strongly associated with hookworm (OR: 16.6) and S. stercoralis (OR: 4.0) infections in infants and with T. trichiura (OR: 3.2 ), hookworm (OR: 2.7), and S. stercoralis (OR: 2.2) infections in SAC. Marked eosinophilia is considered a common marker for early hookworm and S. stercoralis infections, and is explained by the immune reaction to the worm larvae, which migrate through the body tissues to reach their destination in the lungs and in the gastrointestinal tract [13]. The eosinophilia caused by $T$. trichiura is reported to be mostly mild [13]. The hematology values of our study population were only partially in line with reference values derived from a similar study population based in the Kilimanjaro district [51]. Considerably higher neutrophil counts were found in almost a quarter and elevated monocyte, eosinophil, and basophil counts in more than a third of all participants of all age-groups in our study children. While higher eosinophil counts were associated with specific helminth species infections and monocyte counts were associated with asymptomatic Plasmodium parasitemia in some age-groups, the latter being a common sign of acute malaria $[81,82]$, there might be additional underlying reasons such as viral or bacterial infections causing monocytosis or allergies and other diseases causing eosinophilia $[13,83]$. Elevated basophil counts were not associated with helminth or asymptomatic Plasmodium infections in our study, confirming that it is not a useful clinical marker for the evaluation of suspected parasitic disease [84]. Moreover, considering the unpublished reference values used in the IHI-BRTC laboratory, the normal range of basophils at the IHIBRTC is $0.0-0.3$ per $10^{9} / \mathrm{L}$ and thus much higher than the Kilimanjaro values [51] and rather resembling the pediatric reference values reported for Uganda [85]. A limitation of our study is that no other infections or diseases that might have caused elevated or decreased blood cell counts were investigated and there is a clear need for the establishment of standardized hematological reference values for the Bagamoyo area.

\section{Conclusions}

The results of our cross-sectional study showed that E. vermicularis and $S$. stercoralis were moderately prevalent in young children from rural coastal Tanzania. A considerable number of infants were infected and prevalences increased with children's age. Our data can contribute to inform yet missing global burden of disease and prevalence estimates for strongyloidiasis and enterobiasis. The association between S. stercoralis and asymptomatic Plasmodium parasitaemia found in infants of our study population warrants further investigations.

\footnotetext{
Abbreviations

Cl: Confidence interval; CRF: Case report form; DALYs: Disability adjusted life years; EKBB: Ethikkomission beider Basel; EPG: Eggs per gram of stool; FEC: Faecal egg count; HIV-AIDS: Human immunodeficiency virus-acquired immune deficiency syndrome; ICT: Immunochromatic test; IHI-BRTC: Ifakara Health Institute-Bagamoyo Research and Training Centre; MUAC: Mid-upper arm circumference; NIMR: National Institution for Medical Research of Tanzania; OR: Odds ratio; PanACEA: Pan African Collaboration for the Evaluation of Antituberculosis Antibiotics; PSAC: Preschool-aged children; SAC: School-aged children; Swiss TPH: Swiss Tropical and Public Health Institute; TB: Tuberculosis; UNICEF: United Nations Children's Fund; VHCW: Village health care worker; WHO: World Health Organization.
} 


\section{Authors' contributions}

SK analysed the data and drafted the manuscript. BG, SA, MT and CD initiated the study. NS, DK, JM and OL conducted fieldwork and were responsible for the anthropometric and haematological assessments. SK, TS, JR, and ASM implemented and conducted the parasitological examinations. UA cleaned the data. All authors contributed to the full conception and implementation of the study, revised the manuscript and approved its final version.

\section{Acknowledgments}

All authors are grateful for the grant provided by the European Commission under the Health Cooperation Work Program of the 7th Framework Program to conduct part of the IDEA project "Dissecting the Immunological Interplay between Poverty Related Diseases and Helminth infections: An African-European Research Initiative" (http://ec.europa.eu/research/health/infectious-diseases/ neglected-diseases/projects/014_en.html) at IHI-BRTC (Grant agreement $\left.n^{\circ} 241642\right)$

The funders played no role in in design, collection, analysis, and interpretation of data; in the writing of the manuscript; and in the decision to submit the manuscript for publication.

We are particularly obliged to Raymond Singo, Shabani Halfan, Rehaema Mangoli, and Tatu Nassor for their help in the field and laboratory work and the data unit of the IHI-BRTC for entering the large amount of data. Moreover, we acknowledge the Bagamoyo district officials and specifically the district immunization and vaccination officer Farah Mohammed for his great collaboration. Finally, we are grateful to all children and their parents who agreed to participate in this study and submitted blood, stool, and urine samples.

\section{Author details}

${ }^{1}$ Bagamoyo Research and Training Centre, Ifakara Health Institute, Bagamoyo, United Republic of Tanzania. ${ }^{2}$ Department of Pediatrics and Child Health, Muhimbili University Health and Allied Sciences, Dar es Salaam, United Republic of Tanzania. ${ }^{3}$ Department of Epidemiology and Public Health, Swiss Tropical and Public Health Institute, Basel, Switzerland. ${ }^{4}$ University of Basel, Basel, Switzerland. ${ }^{5}$ Department of Medical Parasitology and Infection Biology, Swiss Tropical and Public Health Institute, Basel, Switzerland. ${ }^{6}$ Department of Ambulatory Care and Community Medicine, Infectious Disease Service, Lausanne University Hospital, Lausanne, Switzerland. ${ }^{7}$ Department of Life Sciences, Wolfson Wellcome Biomedical Laboratories, Natural History Museum, London, United Kingdom.

Received: 4 August 2014 Accepted: 20 November 2014

Published online: 09 December 2014

\section{References}

1. Utzinger J, Becker SL, Knopp S, Blum J, Neumayr AL, Keiser J, Hatz CF: Neglected tropical diseases: diagnosis, clinical management, treatment and control. Swiss Med Wkly 2012, 142:W13727.

2. Knopp S, Steinmann P, Keiser J, Utzinger J: Nematode infections: soil-transmitted helminths and Trichinella. Infect Dis Clin North Am 2012, 26(2):341-358

3. Bethony J, Brooker S, Albonico M, Geiger SM, Loukas A, Diemert D, Hotez PJ: Soil-transmitted helminth infections: ascariasis, trichuriasis, and hookworm. Lancet 2006, 367(9521):1521-1532.

4. Pullan RL, Smith JL, Jasrasaria R, Brooker SJ: Global numbers of infection and disease burden of soil transmitted helminth infections in 2010. Parasit Vectors 2014, 7:37.

5. Hotez PJ, Alvarado M, Basáñez MG, Bolliger I, Bourne R, Boussinesq M, Brooker SJ, Brown AS, Buckle G, Budke CM, Carabin H, Coffeng LE, Fevre EM, Fürst T, Halasa YA, Jasrasaria R, Johns NE, Keiser J, King CH, Lozano R, Murdoch ME, O'Hanlon S, Pion SD, Pullan RL, Ramaiah KD, Roberts T, Shepard DS, Smith JL, Stolk WA, Undurraga EA, et al: The Global Burden of Disease Study 2010: interpretation and implications for the neglected tropical diseases. PLoS Negl Trop Dis 2014, 8(7):e2865.

6. Murray CJL, Vos T, Lozano R, Naghavi M, Flaxman AD, Michaud C, Ezzati M, Shibuya K, Salomon JA, Abdalla S, Aboyans V, Abraham J, Ackerman I, Aggarwal R, Ahn SY, Ali MK, Alvarado M, Anderson HR, Anderson LM, Andrews KG, Atkinson C, Baddour LM, Bahalim AN, Barker-Collo S, Barrero LH, Bartels DH, Basáñez MG, Baxter A, Bell ML, Benjamin EJ, et al: Disabilityadjusted life years (DALYs) for 291 diseases and injuries in 21 regions,
1990-2010: a systematic analysis for the Global Burden of Disease Study 2010. Lancet 2012, 380(9859):2197-2223.

7. Krolewiecki AJ, Lammie P, Jacobson J, Gabrielli AF, Levecke B, Socias E, Arias LM, Sosa N, Abraham D, Cimino R, Echazu A, Crudo F, Vercruysse J, Albonico M: A public health response against Strongyloides stercoralis: time to look at soil-transmitted helminthiasis in full. PLoS Negl Trop Dis 2013, 7(5):e2165.

8. Olsen A, van Lieshout L, Marti H, Polderman T, Polman K, Steinmann P, Stothard R, Thybo S, Verweij JJ, Magnussen P: Strongyloidiasis - the most neglected of the neglected tropical diseases? Trans $R$ Soc Trop Med Hyg 2009, 103:967-972

9. Knopp S, Salim N, Schindler T, Karagiannis Voules DA, Abduhl U, Rothen J, Lweno O, Mohammed AS, Genton B, Daubenberger C: Diagnostic accuracy of Kato-Katz, FLOTAC, Baermann and PCR methods for the detection of light intensity hookworm and Strongyloides stercoralis infections in Tanzania. Am J Trop Med 2014, 90(3):535-545.

10. Becker SL, Sieto B, Silue KD, Adjossan L, Kone S, Hatz C, Kern WW, N'Goran EK, Utzinger J: Diagnosis, clinical features, and self-reported morbidity of Strongyloides stercoralis and hookworm infection in a co-endemic setting. PLoS Negl Trop Dis 2011, 5(8):e1292.

11. Montes M, Sawhney C, Barros N: Strongyloides stercoralis: there but not seen. Curr Opin Infect Dis 2010, 23(5):500-504.

12. Greaves D, Coggle S, Pollard C, Aliyu SH, Moore EM: Strongyloides stercoralis infection. BMJ 2013, 347:f4610.

13. Leder K, Weller PF: Eosinophilia and helminthic infections. Baillieres Best Pract Res Clin Haematol 2000, 13(2):301-317.

14. Grove DI: Human strongyloidiasis. Adv Parasitol 1996, 38:251-309.

15. Khieu V, Srey S, Schar F, Muth S, Marti H, Odermatt P: Strongyloides stercoralis is a cause of abdominal pain, diarrhea and urticaria in rural Cambodia. BMC Res Notes 2013, 6:200.

16. Ardic N: [An overview of Strongyloides stercoralis and its infections]. Mikrobiyol Bul 2009, 43(1):169-177.

17. Nuesch R, Zimmerli L, Stockli R, Gyr N, Hatz CFR: Imported strongyloidosis: a longitudinal analysis of 31 cases. J Travel Med 2005, 12:80-84.

18. Segarra-Newnham M: Manifestations, diagnosis, and treatment of Strongyloides stercoralis infection. Ann Pharmacother 2007, 41(12):1992-2001.

19. Schär F, Trostdorf U, Giardina F, Khieu V, Muth S, Marti H, Vounatsou P, Odermatt P: Strongyloides stercoralis: global distribution and risk factors. PLoS Negl Trop Dis 2013, 7(7):e2288.

20. Utzinger J, Raso G, Brooker S, De Savigny D, Tanner M, Ornbjerg N, Singer BH, N'Goran EK: Schistosomiasis and neglected tropical diseases: towards integrated and sustainable control and a word of caution. Parasitology 2009, 136(13):1859--1874.

21. Bisoffi Z, Buonfrate D, Montresor A, Requena-Mendez A, Munoz J, Krolewiecki AJ, Gotuzzo E, Mena MA, Chiodini PL, Anselmi M, Moreira J, Albonico M: Strongyloides stercoralis: a plea for action. PLoS Negl Trop Dis 2013, 7(5):e2214.

22. St Georgiev V: Chemotherapy of enterobiasis (oxyuriasis). Expert Opin Pharmacother 2001, 2(2):267-275.

23. Arca MJ, Gates RL, Groner Jl, Hammond S, Caniano DA: Clinical manifestations of appendiceal pinworms in children: an institutional experience and a review of the literature. Pediatr Surg Int 2004, 20(5):372-375.

24. Burkhart CN, Burkhart CG: Assessment of frequency, transmission, and genitourinary complications of enterobiasis (pinworms). Int J Dermato 2005, 44(10):837-840.

25. Cook GC: Enterobius vermicularis infection. Gut 1994, 35(9):1159-1162

26. Fry GF, Moore JG: Enterobius vermicularis: 10,000-year-old human infection. Science 1969, 166(3913):1620.

27. Nacher M: Interactions between worms and malaria: good worms or bad worms? Malar J 2011, 10:259.

28. Adegnika AA, Kremsner PG: Epidemiology of malaria and helminth interaction: a review from 2001 to 2011. Curr Opin HIV AIDS 2012, 7(3):221-224.

29. Rafi W, Ribeiro-Rodrigues R, Ellner JJ, Salgame P: Coinfection-helminthes and tuberculosis. Curr Opin HIV AIDS 2012, 7(3):239-244.

30. Walson JL, Herrin BR, John-Stewart G: Deworming helminth co-infected individuals for delaying HIV disease progression. Cochrane Database Syst Rev 2009, 3:CD006419.

31. Secor WE: The effects of schistosomiasis on HIV/AIDS infection, progression and transmission. Curr Opin HIV AIDS 2012, 7(3):254-259.

32. Webb EL, Ekii AO, Pala P: Epidemiology and immunology of helminth-HIV interactions. Curr Opin HIV AIDS 2012, 7(3):245-253. 
33. Knopp S, Becker S, Ingram K, Keiser J, Utzinger J: Diagnosis and treatment of schistosomiasis in children in the era of intensified control. Expert Rev Anti Infect Ther 2013, 11(11):1237-1258.

34. Moreau E, Chauvin A: Immunity against helminths: interactions with the host and the intercurrent infections. J Biomed Biotechnol 2010, 2010:428593.

35. McSorley HJ, Hewitson JP, Maizels RM: Immunomodulation by helminth parasites: defining mechanisms and mediators. Int J Parasitol 2013, 43(3-4):301-310.

36. Kinung'hi SM, Magnussen P, Kaatano GM, Kishamawe C, Vennervald BJ: Malaria and helminth co-infections in school and preschool children: a cross-sectional study in Magu district, north-western Tanzania. PLoS One 2014, 9(1):e86510.

37. Salgame P, Yap GS, Gause WC: Effect of helminth-induced immunity on infections with microbial pathogens. Nat Immunol 2013, 14(11):1118-1126.

38. Righetti AA, Glinz D, Adiossan LG, Koua AY, Niamke S, Hurrell RF, Wegmuller R, N'Goran EK, Utzinger J: Interactions and potential implications of Plasmodium falciparum-hookworm coinfection in different age groups in south-central Côte d'Ivoire. PLoS Negl Trop Dis 2012, 6(11):e1889.

39. Mwangi TW, Bethony JM, Brooker S: Malaria and helminth interactions in humans: an epidemiological viewpoint. Ann Trop Med Parasitol 2006, 100(7):551-570.

40. NBS \& OCGS: 2012 Population and Housing Survey of the United Republic of Tanzania. Population Distribution by Administrative Areas. Dar es Salaam: United Republic of Tanzania: National Bureau of Statistics, Ministry of Finance, and Zanzibar, United Republic of Tanzania: Office of Chief Government Statistician, President's Office, Finance, Economy and Development Planning; 2013:21

41. NBS \& CRCO: United Republic of Tanzania Coast Region Socio-Economic Profile. Dar es Salaam: United Republic of Tanzania: National Bureau of Statistics and Coast Regional Commissioner's Office, coordinated by Ministry of Planning, Economy and Empowerment; 2007:127.

42. Greenwood BM, Armstrong JR: Comparison of two simple methods for determining malaria parasite density. Trans R Soc Trop Med Hyg 1991 85(2):186-188.

43. NMCP, WHO, IHI, KEMRI: An Epidemiological Profile of Malaria and its Control in Mainland Tanzania. Report Funded by Roll Back Malaria and Department for International Development-UK. Dar es Salaam: United Republic of Tanzania: National Malaria Control Programme, WHO, Ifakara Health Institute, and Nairobi, Kenya: KEMRI-Wellcome Trust; 2013:151.

44. García LS, Bruckner DA: Diagnostic Medical Parasitology. 4th edition. Washington DC: American Society for Microbiology; 2001.

45. Katz N, Chaves A, Pellegrino J: A simple device for quantitative stool thicksmear technique in schistosomiasis mansoni. Rev Inst Med Trop Sao Paulo 1972, 14(6):397-400.

46. Peters PA, Mahmoud AA, Warren KS, Ouma JH, Siongok TK: Field studies of a rapid, accurate means of quantifying Schistosoma haematobium eggs in urine samples. Bull World Health Organ 1976, 54(2):159-162.

47. Cringoli G, Rinaldi L, Maurelli MP, Utzinger J: FLOTAC: new multivalent techniques for qualitative and quantitative copromicroscopic diagnosis of parasites in animals and humans. Nat Protoc 2010, 5:503-515.

48. Mogeni P, Twahir H, Bandika V, Mwalekwa L, Thitiri J, Ngari M, Toromo C, Maitland K, Berkley JA: Diagnostic performance of visible severe wasting for identifying severe acute malnutrition in children admitted to hospital in Kenya. Bull World Health Organ 2011, 89(12):900-906.

49. WHO \& UNICEF: WHO Child Growth Standards and the Identification of Severe Acute Malnutrition in Infants and Children. Geneva, Switzerland: A Joint Statement by the World Health Organization and the United Nations Children's Fund; 2009.

50. WHO: Haemoglobin Concentrations for the Diagnosis of Anaemia and Assessment of Severity. Geneva, Switzerland: World Health Organization; 2011. http://www.who.int/vmnis/indicators/haemoglobin.pdf, accessed 15.12.2013.

51. Buchanan AM, Muro FJ, Gratz J, Crump JA, Musyoka AM, Sichangi MW, Morrissey AB, M'Rimberia JK, Njau BN, Msuya LJ, Bartlett JA, Cunningham CK: Establishment of haematological and immunological reference values for healthy Tanzanian children in Kilimanjaro Region. Trop Med Int Health 2010, 15(9):1011-1021.

52. Kohl KS, Marcy SM, Blum M, Connell Jones M, Dagan R, Hansen J, Nalin D, Rothstein E: Brighton Collaboration Fever Working G: fever after immunization: current concepts and improved future scientific understanding. Clin Infect Dis 2004, 39(3):389-394.
53. Montresor A, Crompton DWT, Hall A, Bundy DAP, Savioli L: Guidelines for the Evaluation of Soil-Transmitted Helminthiasis and Schistosomiasis at Community Level. Geneva, Switzerland: World Health Organization; 1998.

54. Raso G, Vounatsou P, Singer BH, N'Goran EK, Tanner M, Utzinger J: An integrated approach for risk profiling and spatial prediction of Schistosoma mansoni-hookworm coinfection. Proc Natl Acad Sci U S A 2006, 103(18):6934-6939.

55. Knopp S, Mohammed KA, Stothard JR, Khamis IS, Rollinson D, Marti H, Utzinger J: Patterns and risk factors of helminthiasis and anemia in a rural and a peri-urban community in Zanzibar, in the context of helminth control programs. PLoS Negl Trop Dis 2010, 4(5):e681.

56. Tatala SR, Kihamia CM, Kyungu LH, Svanberg U: Risk factors for anaemia in schoolchildren in Tanga Region. Tanzania Tanzan J Health Res 2008, 10(4):189-202

57. Nyhus Dhillon C, Subramaniam H, Mulokozi G, Rambeloson Z, Klemm R: Overestimation of vitamin a supplementation coverage from district tally sheets demonstrates importance of population-based surveys for program improvement: lessons from Tanzania. PLoS One 2013, 8(3):e58629.

58. Mwakitalu ME, Malecela MN, Mosha FW, Simonsen PE: Urban schistosomiasis and soil transmitted helminthiases in young school children in Dar es Salaam and Tanga, Tanzania, after a decade of anthelminthic intervention. Acta Trop 2014, 133:35-41

59. Gryseels B: Schistosomiasis. Infect Dis Clin North Am 2012, 26(2):383-397.

60. Knopp S, Mgeni AF, Khamis IS, Steinmann P, Stothard JR, Rollinson D, Marti H, Utzinger J: Diagnosis of soil-transmitted helminths in the era of preventive chemotherapy: effect of multiple stool sampling and use of different diagnostic techniques. PLoS Negl Trop Dis 2008, 2(11):e331.

61. Jeandron A, Abdyldaieva G, Usubalieva J, Ensink JH, Cox J, Matthys B, Rinaldi L, Cringoli G, Utzinger J: Accuracy of the Kato-Katz, adhesive tape and FLOTAC techniques for helminth diagnosis among children in Kyrgyzstan. Acta Trop 2010, 116(3):185-192.

62. Hillier SD, Booth M, Muhangi L, Nkurunziza P, Khihembo M, Kakande M, Sewankambo M, Kizindo R, Kizza M, Muwanga M, Elliott AM: Plasmodium falciparum and helminth coinfection in a semi urban population of pregnant women in Uganda. J Infect Dis 2008, 198(6):920-927.

63. Stothard JR, Pleasant J, Oguttu D, Adriko M, Galimaka R, Ruggiana A Kazibwe F, Kabatereine NB: Strongyloides stercoralis: a field-based survey of mothers and their preschool children using ELISA, Baermann and Koga plate methods reveals low endemicity in western Uganda. J Helminthol 2008, 82(3):263-269.

64. Joyce T, McGuigan KG, Elmore-Meegan M, Conroy RM: Prevalence of enteropathogens in stools of rural Maasai children under five years of age in the Maasailand region of the Kenyan Rift Valley. East Afr Med J 1996, 73(1):59-62.

65. Tanner M, Burnier E, Mayombana C, Betschart B, de Savigny D, Marti HP Suter R, Aellen M, Lüdin E, Degrémont AA: Longitudinal study on the health status of children in a rural Tanzanian community: parasitoses and nutrition following control measures against intestinal parasites. Acta Trop 1987, 44(2):137-174.

66. Keiser J, Utzinger J: Efficacy of current drugs against soil-transmitted helminth infections: systematic review and meta-analysis. JAMA 2008, 299(16):1937-1948.

67. Mazigo HD, Kidenya BR, Ambrose EE, Zinga M, Waihenya R: Association of intestinal helminths and $P$. falciparum infections in co-infected school children in northwest Tanzania. Tanzan J Health Res 2010, 12(4):283-285.

68. Shapiro AE, Tukahebwa EM, Kasten J, Clarke SE, Magnussen P, Olsen A, Kabatereine NB, Ndyomugyenyi R, Brooker S: Epidemiology of helminth infections and their relationship to clinical malaria in southwest Uganda. Trans R Soc Trop Med Hyg 2005, 99(1):18-24.

69. Boel M, Carrara VI, Rijken M, Proux S, Nacher M, Pimanpanarak M, Paw MK, Moo O, Gay H, Bailey W, Singhasivanon P, White NJ, Nosten F, McGready R: Complex interactions between soil-transmitted helminths and malaria in pregnant women on the Thai-Burmese border. PLoS Negl Trop Dis 2010, 4(11):e887.

70. Tanner M, Lukmanji Z: Food consumption patterns in a rural Tanzanian community (Kikwawila village, Kilombero District, Morogoro Region) during lean and post-harvest season. Acta Trop 1987, 44(2):229-244.

71. Tanner M, de Savigny D: Monitoring of community health status: experience from a case study in Tanzania. Acta Trop 1987, 44(2):261-270.

72. MUCHALI: Comprehensive Food Security and Nutrition Assessment Report of the April, 2012 Main (Masika) Season. Dar es Salaam: United Republic of 
Tanzania: Report coordinated by the Disaster Management Department Prime Minister's Office and The National Food Security Division - Ministry of Agriculture Food Security and Co-operatives and prepared by the Tanzania Food Security and Nutrition Analysis System - MUCHALl; 2012:32.

73. Gyorkos TW, Maheu-Giroux M, Casapia M, Joseph SA, Creed-Kanashiro H: Stunting and helminth infection in early preschool-age children in a resource-poor community in the Amazon lowlands of Peru. Trans $R$ Soc Trop Med Hyg 2011, 105(4):204-208.

74. Sanchez AL, Gabrie JA, Usuanlele MT, Rueda MM, Canales M, Gyorkos TW: Soil-transmitted helminth infections and nutritional status in school-age children from rural communities in Honduras. PLoS Negl Trop Dis 2013, 7(8):e2378.

75. Shang Y, Tang LH, Zhou SS, Chen YD, Yang YC, Lin SX: Stunting and soiltransmitted-helminth infections among school-age pupils in rural areas of southern China. Parasit Vectors 2010, 3:97.

76. Kurtzhals JA, Addae MM, Akanmori BD, Dunyo S, Koram KA, Appawu MA, Nkrumah FK, Hviid L: Anaemia caused by asymptomatic Plasmodium falciparum infection in semi-immune African schoolchildren. Trans $R$ Soc Trop Med Hyg 1999, 93(6):623-627.

77. Smith JL, Brooker S: Impact of hookworm infection and deworming on anaemia in non-pregnant populations: a systematic review. Trop Med Int Health 2010, 15(7):776-795.

78. Brooker S, Hotez PJ, Bundy DAP: Hookworm-related anaemia among pregnant women: a systematic review. PLoS Negl Trop Dis 2008, 2(9):e291.

79. Dreyfuss ML, Stoltzfus RJ, Shrestha JB, Pradhan EK, LeClerq SC, Khatry SK, Shrestha SR, Katz J, Albonico M, West KP Jr: Hookworms, malaria and vitamin A deficiency contribute to anemia and iron deficiency among pregnant women in the plains of Nepal. J Nutr 2000, 130(10):2527-2536.

80. Stoltzfus RJ, Chwaya HM, Montresor A, Albonico M, Savioli L, Tielsch JM: Malaria, hookworms and recent fever are related to anemia and iron status indicators in 0 - to 5 -y old Zanzibari children and these relationships change with age. J Nutr 2000, 130(7):1724-1733.

81. Antonelli LR, Leoratti FM, Costa PA, Rocha BC, Diniz SQ, Tada MS, Pereira DB, Teixeira-Carvalho A, Golenbock DT, Goncalves R, Gazzinelli RT: The CD14 + CD16+ inflammatory monocyte subset displays increased mitochondrial activity and effector function during acute Plasmodium vivax malaria. PLoS Pathog 2014, 10(9):e1004393.

82. Halim NKD, Ajayi Ol, Oluwafemi F: Monocytosis in acute malaria infection. Niger J Clin Pract 2002, 5(2):106-108.

83. Schulte C, Krebs B, Jelinek T, Nothdurft HD, von Sonnenburg F, Loscher T: Diagnostic significance of blood eosinophilia in returning travelers. Clin Infect Dis 2002, 34(3):407-411.

84. Mitre E, Nutman TB: Lack of basophilia in human parasitic infections. Am J Trop Med Hyg 2003, 69(1):87-91.

85. Lugada ES, Mermin J, Kaharuza F, Ulvestad E, Were W, Langeland N, Asjo B, Malamba S, Downing R: Population-based hematologic and immunologic reference values for a healthy Ugandan population. Clin Diagn Lab Immunol 2004, 11(1):29-34.

doi:10.1186/s12879-014-0644-7

Cite this article as: Salim et al:: Enterobiasis and strongyloidiasis and associated co-infections and morbidity markers in infants, preschooland school-aged children from rural coastal Tanzania: a cross-sectional study. BMC Infectious Diseases 2014 14:644.

\section{Submit your next manuscript to BioMed Central and take full advantage of:}

- Convenient online submission

- Thorough peer review

- No space constraints or color figure charges

- Immediate publication on acceptance

- Inclusion in PubMed, CAS, Scopus and Google Scholar

- Research which is freely available for redistribution 